\title{
Diagnosing Ocean Tracer Transport from Sellafield and Dounreay by Equivalent Diffusion and Age
}

\author{
Steinar ORRE ${ }^{* 1,2}$, Yongqi $\mathrm{GAO}^{1,2,3}$, Helge DRANGE ${ }^{1,2,3,4}$, and Eric DELEERSNIJDER ${ }^{5}$ \\ ${ }^{1}$ Nansen Environmental and Remote Sensing Center, Bergen, Norway \\ ${ }^{2}$ Bjerknes Centre for Climate Research, Bergen, Norway \\ ${ }^{3}$ Nansen-Zhu International Research Centre, Institute of Atmospheric Physics (IAP), \\ Chinese Academy of Sciences (CAS), Beijing 100029 \\ ${ }^{4}$ Geophysical Institute, University of Bergen, Bergen, Norway \\ ${ }^{5}$ Centre for Systems Engineering and Applied Mechanics (CESAME), Louvain School of Engineering, \\ Universite catholique de Louvain, Louvain-la-Neuve, Belgium
}

(Received 2 August 2007; revised 28 January 2008)

\begin{abstract}
A simple approach for estimating the equivalent diffusion for diagnosing tracer transport is proposed. Two different expressions are derived; one is based directly on an analytical solution of the two-dimensional advection-diffusion equation, the other uses the variance of the tracer distribution. To illustrate some features of the equivalent diffusion and possible applications thereof, idealized releases of passive tracers from the nuclear fuel reprocessing plants at Sellafield in the Irish Sea and Dounreay on the northern coast of Scotland have been simulated with a regional isopycnic co-ordinate Ocean General Circulation Model. Both continuous and pulse releases are considered; the former being representative of the actual historical discharges from the reprocessing plants, the latter resembling an accidental scenario. Age tracers are included to calculate the mean time elapsed since the tracers left their source regions. It is found that in the Nordic Seas the age of tracers from Dounreay is approximately 2 years younger than the age from Sellafield. Although tracers from both sources eventually end up along the same transport routes, significant qualitative differences regarding the dispersion properties are found. It is argued that one single parameter, the equivalent horizontal diffusion, which is estimated to be in the range of $20-56 \mathrm{~m}^{2} \mathrm{~s}^{-1}$ from Sellafield and $170-485 \mathrm{~m}^{2} \mathrm{~s}^{-1}$ from Dounreay, determines these differences.
\end{abstract}

Key words: equivalent diffusion, passive tracers, age tracers, sellafield, dounreay

Citation: Orre, S., Y. Q. GAO, H. Drange, and E. Deleersnijder, 2008: Diagnosing ocean tracer transport from sellafield and dounreay by equivalent diffusion and age. Adv. Atmos. Sci., 25(5), 805-814, doi: 10.1007/s00376-008-0805-y.

\section{Introduction}

Estimating the integrated effect of processes acting to spread any tracer signal carried by currents in the ocean is of crucial importance for environmental studies. The presence of numerous contaminant sources and the need to predict the circulation of biogeochemical tracers influencing the oceanic carbon cycle are just two examples of where such information is needed. In an Ocean General Circulation Model (OGCM) these mixing processes are not only an effect of the parameterized isopycnal and diapycnal diffusion, but also every other effect acting to spread and dilute a tracer patch, e.g. velocity shear and mesoscale eddies.

This paper does not intend to contribute to the chaotic dispersion paradigm of mixing in the ocean (e.g., Wiggins, 2005; Orre et al., 2006), but rather the more traditional, statistical approach associated

\footnotetext{
*Corresponding author: Steinar ORRE, steinar.orre@nersc.no
} 
with the turbulent diffusion paradigm (e.g., Okubo, 1971). From a simplified two-dimensional advectiondiffusion equation with a pulse released in an infinite domain, one can derive two explicit expressions for the equivalent diffusion ${ }^{\mathrm{a}}$ — or the integrated measure of the spreading. Here, we apply similar relations to an OGCM that is used to simulate tracer concentration from idealized pulse releases from the British nuclear fuel reprocessing plants at Sellafield and Dounreay. Advanced methods for extracting the equivalent diffusion have been developed and applied to both atmospheric (Haynes and Shuckburgh, 2000) and oceanic flows (Marshall et al., 2006), however, a simpler approach is taken here that is tailored for tracers with a point source release.

European nuclear reprocessing plants have performed controlled releases of liquid radioactive waste into the ocean since the early 1950s (Dahlgaard, 1995). The reprocessing plants at Sellafield in the Irish Sea are still in operation, while releases from Dounreay on the northern coast of Scotland have now ceased (AMAP, 2004). In a pioneering work by Prandle (1984), mixing and time-scales of the radionuclide ${ }^{137} \mathrm{Cs}$ on the European continental shelf was investigated. More recently, it has been shown that the current generation of OGCMs are capable of simulating the large-scale dispersion (Nordic Seas and the Arctic Ocean) of radionuclides from both European reprocessing plants and atmospheric fallout from nuclear bomb testing in a realistic manner (e.g., Karcher et al., 2004; Gao et al., 2004).

In a companion paper (Orre et al., 2007) dispersion of ${ }^{99} \mathrm{Tc}$ has been simulated for the time period of 1975 to 2003 with the same model setup as the one used in this study. After relatively low release rates of ${ }^{99} \mathrm{Tc}$ during the $1980 \mathrm{~s}$ and the early 1990s, a rapid increase from Sellafield started from April 1994. This "pulse" of ${ }^{99} \mathrm{Tc}$ was observed in the Barents Sea region several years later (e.g., Kershaw et al., 2004). In Orre et al. (2007) it was demonstrated that the model reproduced the observed values on the north coast of Norway fairly accurately.

It is, however, a challenge to infer transport properties using "real" tracers like ${ }^{99} \mathrm{Tc}$ with variable release rates. In general, tracers with different release rates produce different estimates of transport properties, e.g., the age of tracers and dilution of the concentration downstream of the source region (Waugh et al., 2003). Therefore, in this study, an effort is made to isolate the effect of ocean dynamics on the dispersion properties of the tracer by using idealized release rates. For the initial location of the tracers, the two nuclear fuel reprocessing plants of Sellafield in the Irish Sea and Dounreay on the northern coast of Scotland are chosen. We choose to focus on British nuclear reprocessing plants in this study, although releases from La Hague on the French coast in the English Channel have been another major source of radioactive waste. The reprocessing plant in Dounreay is no longer in operation. However, assessing the evolution of passive tracers from this location along with tracers from Sellafield will highlight the qualitative difference between having the tracer source near the Atlantic Inflow on the Scottish Shelf or in a semi-enclosed basin like the Irish Sea. Whether one can quantify this difference in terms of a simple time lag in the resulting tracer concentration downstream of the source is examined. Finally, we show how these idealized tracers compare with both simulated and observed values of ${ }^{99} \mathrm{Tc}$.

\section{Equivalent diffusion derived from a 2-D model}

Consider a two-dimensional advection-diffusion problem over an infinite domain. Let $\boldsymbol{x}_{\mathrm{h}}=(x, y)$ and $t$ denote the position vector and time, where the horizontal domain is $-\infty<x<\infty,-\infty<y<\infty$, and the time $0 \leqslant t<\infty$. The Green's function $G$ is then the solution to the following advection-diffusion problem with a unit release in space and time:

$$
\frac{\partial G}{\partial t}+\nabla \cdot(\boldsymbol{U} G-K \nabla G)=\delta\left(\boldsymbol{x}_{\mathrm{h}}-0\right) \delta(t-0) .
$$

Here $\boldsymbol{U}\left(\boldsymbol{x}_{\mathrm{h}}\right)$ is a constant velocity vector of the flow and $K$ is a constant diffusion coefficient. The Green's function is such that

$$
\int_{-\infty}^{\infty} \int_{-\infty}^{\infty} G\left(\boldsymbol{x}_{\mathrm{h}}, t\right) d x d y=1
$$

implying that the dimension of $G$ is $\mathrm{m}^{-2}$. Equation 1 has the following analytical solution (e.g., Morse and Feshbach, 1953):

$$
G\left(\boldsymbol{x}_{\mathrm{h}}, t\right)=\frac{1}{4 \pi K t} \exp \left[-\frac{\left(\boldsymbol{x}_{\mathrm{h}}-\boldsymbol{U} t\right)^{2}}{4 K t}\right],
$$

where the maximum value of $G$ is

$$
G_{\max }(t)=\frac{1}{4 \pi K t}
$$

and is located at $\boldsymbol{x}_{\max }=\boldsymbol{U} t$. Localizing the maximum value of $G$ will then provide an explicit expression of the horizontal diffusivity, i.e., $K=1 /\left(4 \pi G_{\max } t\right)$.

${ }^{a}$ Both effective and equivalent diffusion can be seen in the literature, having the same physical meaning. We will use equivalent diffusion throughout the text. 
We continue with defining the variance $\sigma^{2}$ of the tracer distribution

$$
\sigma^{2}=\frac{\int_{-\infty}^{\infty} \int_{-\infty}^{\infty} G\left(\boldsymbol{x}_{\mathrm{h}}, t\right)\left|\boldsymbol{x}_{\mathrm{h}}-\mathbf{x}_{\max }\right|^{2} d x d y}{\int_{-\infty}^{\infty} \int_{-\infty}^{\infty} G\left(\boldsymbol{x}_{\mathrm{h}}, t\right) d x d y}
$$

Setting $r=\left|\boldsymbol{x}_{\mathrm{h}}-\boldsymbol{x}_{\max }\right|^{2}$, Eq. (5) can then be transformed to

$$
\sigma^{2}=\frac{\int_{0}^{\infty} r^{3} \mathrm{e}^{-r^{2} /(4 K t)} d r}{\int_{0}^{\infty} r \mathrm{e}^{-r^{2} /(4 K t)} d r}
$$

which yields the simple relation

$$
\sigma^{2}=4 K t
$$

Hence, the variance of the tracer distribution $G$ provides a second explicit expression of the horizontal diffusivity, i.e., $K=\sigma^{2} /(4 t)$.

To obtain a 2-D field of the tracer concentration from a 3-D OGCM, we define the tracer inventory as the depth integrated tracer concentration;

$$
\Theta\left(\boldsymbol{x}_{\mathrm{h}}, t\right)=\int_{-h}^{\eta} C\left(\boldsymbol{x}_{\mathrm{h}}, z, t\right) d z
$$

where $-h$ is the sea bed and $\eta$ is the sea surface, and where $z$ denotes the vertical coordinate. The inventory should be normalized to satisfy Eq. (2);

$$
\theta\left(\boldsymbol{x}_{\mathrm{h}}, t\right)=\frac{\Theta\left(\boldsymbol{x}_{\mathrm{h}}, t\right)}{\int_{\Omega} \Theta\left(\boldsymbol{x}_{\mathrm{h}}, t\right) d \boldsymbol{x}_{\mathrm{h}}},
$$

where $\Omega$ is the model domain. Equation (4) then suggests a first estimate of the equivalent horizontal diffusivity as

$$
K_{\mathrm{eq}} \simeq \frac{1}{4 \pi t \theta_{\max }}
$$

For $K_{\text {eq }}$ to be constant in time, the maximum value of the normalized inventory $\theta_{\max }$ should decrease as $t^{-1}$.

The variance of the distribution of the normalized inventory is defined in a similar way as the variance for the Green's function;

$$
\mu^{2}=\frac{\int_{\Omega} \theta\left(\boldsymbol{x}_{\mathrm{h}}, t\right)\left|\boldsymbol{x}_{\mathrm{h}}-\boldsymbol{x}_{\max }\right|^{2} d \boldsymbol{x}_{\mathrm{h}}}{\int_{\Omega} \theta\left(\boldsymbol{x}_{\mathrm{h}}, t\right) d \boldsymbol{x}_{\mathrm{h}}} .
$$

A second estimate of the equivalent horizontal diffusivity can then be expressed as

$$
K_{\mathrm{eq}}^{\prime} \simeq \frac{\mu^{2}}{4 t} .
$$

From this expression we see that the variance of the distribution of the normalized tracer inventory $\mu^{2}$ should grow approximately as $t$ for $K_{\text {eq }}^{\prime}$ to be constant.

Since the restrictions made for deriving these expressions for the equivalent diffusion are rather strict, we do not expect a precise relationship between them when applied to a complex flow field. However, if $K_{\text {eq }}$ and $K_{\text {eq }}^{\prime}$ yield comparable values from an OGCM, it would support the use of these simple relations in deriving a numerical value of $K$.

\section{Illustration with an OGCM}

\subsection{OGCM and experimental setup}

The model system applied in this study is a nested, medium-resolution regional version of the $\mathrm{Mi}$ ami Isopycnic Coordinate Ocean Model (Bleck et al., 1992). The horizontal grid resolution in the region of interest is about $20 \mathrm{~km}$, and the model domain covers the northern North Atlantic Ocean and the Nordic Seas, geographically bounded between $30^{\circ} \mathrm{N}$ and $80^{\circ} \mathrm{N}$. The OGCM is driven by the NCEP/NCAR daily atmospheric forcing fields, and has shown good skill in reproducing the Atlantic Inflow to the Nordic Seas for the last few decades (e.g., Drange et al., 2005; Hatun et al., 2005). For the parameterized tracer diffusion coefficients, we adopt isopycnal and diapycnal diffusion velocities in close resemblance to the recommendations from Gao et al. (2003) based on simulated uptake of CFCs in the North Atlantic Ocean.

The spatial and temporal evolution of the concentration for a conservative tracer are governed by the linear Eulerian transport equation;

$$
\frac{\partial C}{\partial t}+\nabla \cdot(\boldsymbol{v} C-\boldsymbol{K} \cdot \nabla C)=q .
$$

Here $C(\boldsymbol{x}, t)$ is the tracer concentration, $\boldsymbol{v}(\boldsymbol{x}, t)$ is the velocity field, $\boldsymbol{K}$ is the diffusivity tensor, $q(\boldsymbol{x}, t)$ is the source function, and the space coordinate is $\boldsymbol{x}=(x, y, z)$. In addition, we add an Eulerian age tracer following Deleersnijder et al. (2001);

$$
\frac{\partial \alpha}{\partial t}+\nabla \cdot(\boldsymbol{v} \alpha-\boldsymbol{K} \cdot \nabla \alpha)=C
$$

Here the age concentration is given by $\alpha(\boldsymbol{x}, t)=$ $a(\boldsymbol{x}, t) \cdot C(\boldsymbol{x}, t)$, hence the age $a=\alpha / C$. The age is prescribed to be zero at the source point ${ }^{\mathrm{b}}$. The tracer equations are discretized on a C-grid, consistent with the other prognostic equations in the applied OGCM (see Drange et al., 2005), and are run online.

We will only consider point sources, so the release

\footnotetext{
${ }^{b}$ Note that an alternative approach is possible. In Beckers et al. (2001) the age of the tracer particles leaving the point source was assumed to be zero-leading to a non-zero mean age at the location of the source.
} 
rate will be of the form

$$
q(\boldsymbol{x}, t)=Q(t) \delta\left(\boldsymbol{x}-\boldsymbol{x}_{s}\right),
$$

where $\delta\left(\boldsymbol{x}-\boldsymbol{x}_{s}\right)$ is the Dirac delta function at the source $\boldsymbol{x}_{s}$, and $Q(t)$ is an arbitrary release rate. As already seen from Eq. (1), releasing a unit amount of tracer from a point source $\boldsymbol{x}_{s}$ at $t_{0}$, that is setting $Q(t)=\delta\left(t-t_{0}\right)$, corresponds to the Green's function $G\left(\boldsymbol{x}, \boldsymbol{x}_{s}, t, t_{0}\right)$ of the tracer transport equation if the velocity field is constant in time. One advantage of considering the Green's function is that it has the physical interpretation of being within the possible range of different ages, commonly referred to as the transit time distribution (TTD), since a tracer at $\boldsymbol{x}$ last made contact with the source region $\boldsymbol{x}_{\mathrm{S}}$ (Holzer and Hall, 2000; Haine and Hall, 2002; Delhez and Deleersnijder, 2002). In addition, the TTD is consistent with the age, as defined by Eq. (14), i.e., the age equals the mean of the TTD (Haine and Hall, 2002). If one integrates the tracer equations over a time-averaged velocity field

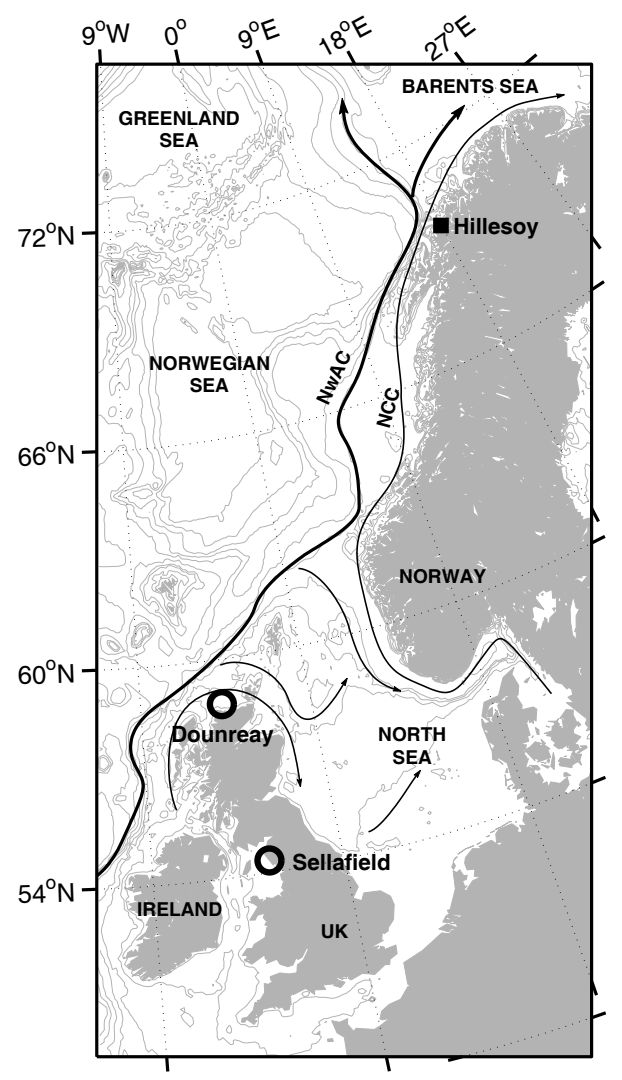

Fig. 1. Schematics of the North Sea and the Nordic Seas region carrying radionuclides from Sellafield and Dounreay to the Barents Sea and further into the Arctic Ocean. The Norwegian Atlantic Current (NwAC) and the Norwegian Coastal Current (NCC) are depicted. Isobaths are drawn for every $50 \mathrm{~m}$ to $200 \mathrm{~m}$ and thereafter for every $500 \mathrm{~m}$. (offline tracer integration), it is sufficient to calculate one $G$. For time-dependent flows, $G\left(\boldsymbol{x}, \boldsymbol{x}_{s}, t, t_{0}\right)$ is only valid as a TTD for a pulse released at time $t_{0}$. However, adding numerous extra tracers in an OGCM will significantly increase the computational resources needed, making this approach less feasible. For comparison with the age tracers, we will, nevertheless, compare the two simulated pulses from Sellafield and Dounreay with the age tracers, keeping in mind that the distribution could be slightly different when released at another period of time, with another ocean state.

As a reference period, we choose to focus on the period from the late 1980s to the present. This is to supplement the many studies of ${ }^{99} \mathrm{Tc}$ in this period (e.g., Kershaw et al., 2004; Karcher et al., 2004; Orre et al., 2007). We consider the following idealized release rates from Sellafield and Dounreay:

(1) A pulse released on 1 January 1989 (pulse 1).

(2) A pulse released on 1 July 1989 (pulse 2).

(3) A continuous release starting from the 1 January 1988.

We specify the continuous release as $10^{12}$ nondimensional units per month. This is comparable to the releases of ${ }^{99} \mathrm{Tc}$ in the late $1990 \mathrm{~s}\left(\sim 10^{12} \mathrm{Bec}-\right.$ querel per month). The pulse-releases are specified as an instantaneous dumping of $10^{14}$ units. Simulated concentration in seawater will be presented in units of $\mathrm{m}^{-3}$.

The geographical regions of the nuclear reprocessing plants in Sellafield and Dounreay are depicted in Fig. 1, along with schematics of the main features of the current systems involved in transporting the tracers northward.

\subsection{The equivalent diffusion from Sellafield and Dounreay}

We first consider the growth of the variance $\mu^{2}$ as defined by Eq. (11). The variance over the first three years from Sellafield and Dounreay derived from the pulse (1) release is shown in Fig. 2. The growth of $\mu^{2}$ from Sellafield during most of the first year is about one order of magnitude less than the growth from Dounreay. The growth of the variance from the two sources after the initial year is comparable. We also observe that the variance from Dounreay is much "smoother" than the abrupt changes in the variance from Sellafield. It has been shown that the oceanic volume transport out of the Irish Sea is event-driven, which, to a large extent, is determined by the amount of along-channel winds (Davies and Hall, 2000). The variance from Sellafield will reflect these oscillating outflow events, while the variance from Dounreay will be governed by the more steady circulation on the 


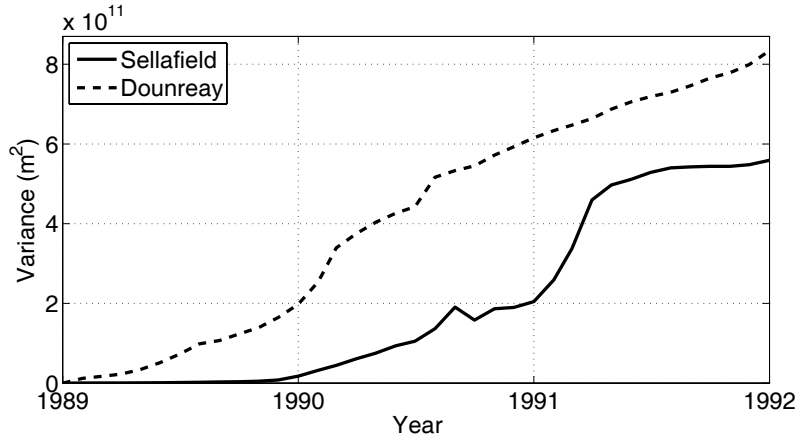

Fig. 2. The simulated variance from Sellafield and Dounreay derived from the pulse (1) release.

Table 1. Estimated equivalent horizontal diffusivity $\left(\mathrm{m}^{2} \mathrm{~s}^{-1}\right)$ from Sellafield and Dounreay based on Eq. (10) for $K_{\text {eq }}$, and Eq. (12) for $K_{\text {eq }}^{\prime}$.

\begin{tabular}{lrrrrr}
\hline & \multicolumn{2}{c}{ pulse (1) } & & \multicolumn{2}{c}{ pulse (2) } \\
\cline { 2 - 3 } \cline { 6 - 7 } & $K_{\text {eq }}$ & $K_{\text {eq }}^{\prime}$ & & $K_{\text {eq }}$ & $K_{\text {eq }}^{\prime}$ \\
\hline Sellafield & 56 & 20 & & 35 & 22 \\
Dounreay & 366 & 485 & & 170 & 288 \\
\hline
\end{tabular}

Scottish Shelf which is strongly influenced by the Atlantic Inflow to the North Sea.

Based on the two simple relations in Eqs. (10) and (12), averaged values of the horizontal diffusivity $K_{\text {eq }}$ have been computed and are provided in Table 1 . This approach would be a crude approximation of the equivalent horizontal diffusivity for the simulated period as a whole since the tracers experience different mixing regimes along the northward pathways. A relatively small amount of tracers from Sellafield will escape the North Channel within the first year after the release, see Fig. 3a, hence reaching a quite different mixing regime in the Scottish Coastal Current and further into the North Sea. About one year after the release the tracers from Dounreay will begin to accumulate in the deeper region of Skagerak, see Fig. 3c. The decrease of $\theta_{\max }$ will therefore be slower than $t^{-1}$ in this period. Therefore, the estimates of the equivalent horizontal diffusivity are based on results from the first year of simulated spreading of the pulses, and should be seen as initial values near the source region.

The equivalent horizontal diffusivity from Sellafield is almost an order of magnitude lower than that from Dounreay: 20-56 $\mathrm{m}^{2} \mathrm{~s}^{-1}$ compared to $170-485 \mathrm{~m}^{2} \mathrm{~s}^{-1}$, respectively. We observe that the values from pulse (1) released from Dounreay are much higher than the values from pulse (2). This is most likely a direct effect of enhanced circulation in the region during the winter months of 1989 compared to the summer. From Sellafield, the estimate based on the decrease of $\theta_{\max }$ is slightly higher for pulse (1) than pulse (2), while the estimate based on the variance of the tracer distribution $\mu^{2}$ is almost the same for the two pulses.

\subsection{Spatial distribution}

From Sellafield in the Irish Sea, the dominant pathway is northward through the North Channel. Tracers from Dounreay are eventually transported along the same pathways into the North Sea and further north, mainly with the Norwegian Coastal Current (NCC), but also mixed with the outer-laying Norwegian Atlantic Current (NwAC), see schematics in Fig. 1. After leaving the Norwegian Sea, tracers are carried into the Arctic Ocean through both the Barents Sea and the Fram Strait. There is also a branch being transported southwards along the east Greenland coast. A more thorough description of tracer transport from Sellafield and possible forcing mechanisms are given in Kershaw et al. (2004) and Orre et al. (2007).

The simulated surface distributions of the tracers with the pulse ${ }^{c}$ release rate are displayed in Fig. 3. While the Dounreay-derived pulse is transported away from the Norwegian coast and the Barents Sea in March 2002 (Fig. 3d) the pulse released from Sellafield in January 1989 is still leaking out from the North Channel more than thirteen years later (Fig. $3 \mathrm{~b})$.

The simulated surface distributions of the tracers with continuous release rate at the end of the simulated period are displayed in Figs. 4a and 4c. There are only minor differences in the concentration away from the source regions at this time, indicating that a continuous release of contaminants from these sources will result in the same long-term environmental impact along the Norwegian coast and beyond.

The age of the Sellafield-derived tracers is in the range $3-6$ years along the Norwegian coast, and reaches up to 10 years in the interior of the Nordic Seas (Fig. 4b). Dounreay tracers are significantly younger, approximately 2 years on average (Fig. 4d). A distinct, sharp boundary is seen between tracers transported northward with the NCC and the NwAC, and the relatively old tracers that has been recirculated in the Nordic Seas. This is particularly evident from the Sellafield age field (Fig. 4b) along the Norwegian coast, where relatively old (9-10 years) tracers in the interior of the Nordic Seas borders younger tracers carried with the NwAC (3-4 years), but then with slightly older tracers close to the Norwegian coast (5-6 years).

${ }^{\mathrm{c}}$ Only pulse (1) is contoured on the maps in Fig. 3 and Fig. 4, and plotted as a function of time in Fig. 5 . Tracers with pulse (2) release rate experience similar behavior. 


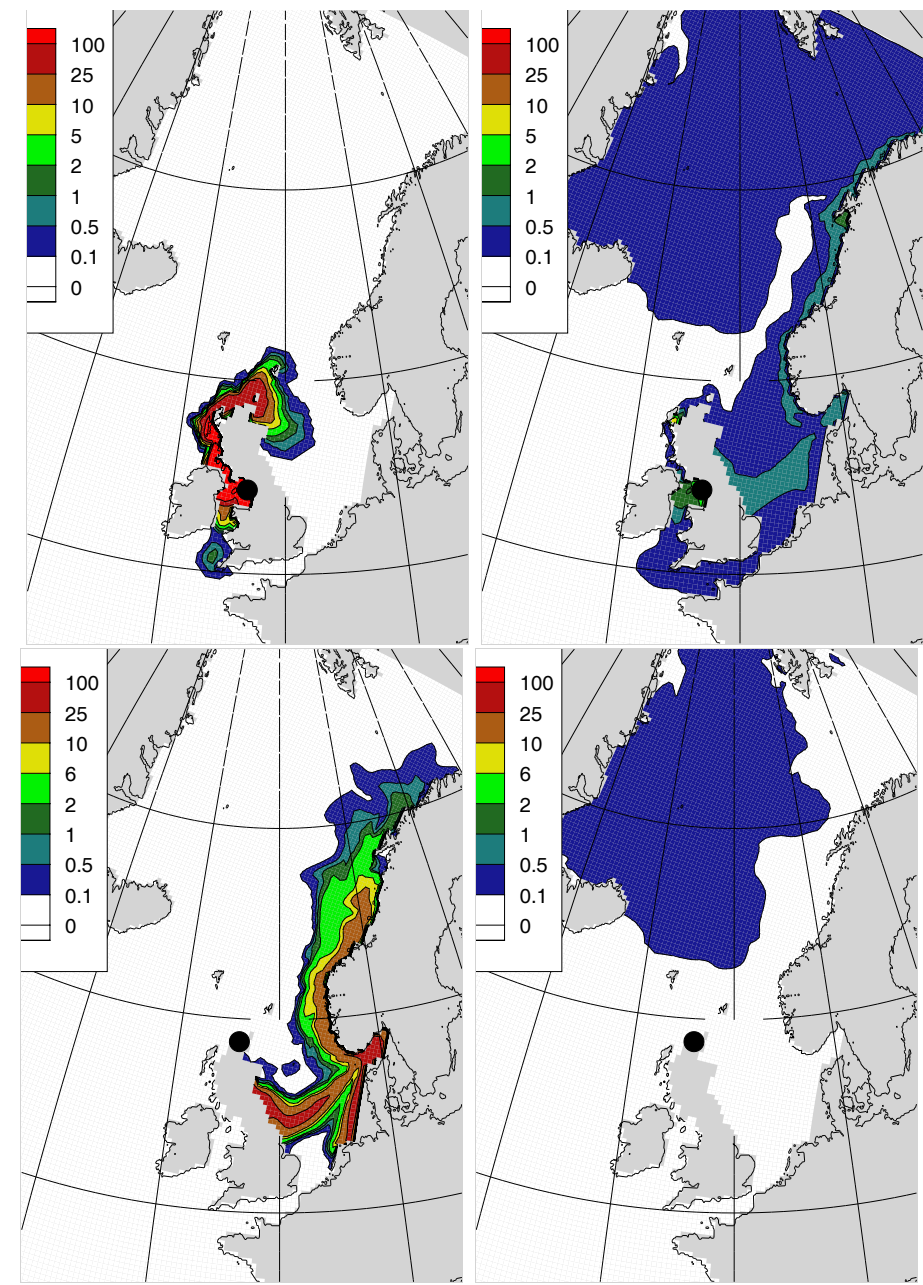

Fig. 3. Simulated surface values (dimensionless units: $\mathrm{m}^{-3}$ ) from the pulse (1) release in (upper-left panel and lower-left panel) March 1990 and (upper-right panel and lower-right panel) March 2002. Upper panel displays tracers from Sellafield, lower panel tracers from Dounreay, source region indicated with the black dot. The surface is defined as the upper $200 \mathrm{~m}$.

This feature does not follow from the concentration field, where a high concentration of tracers tends to stick to the NCC close to the Norwegian coast, in accordance to the general circulation pattern. However, it should be noted that the age field does not necessarily reflect the circulation pattern, in contrast to the concentration field (Beckers et al., 2001).

\subsection{Temporal distribution}

To illustrate the temporal evolution at a station far away from both source regions, we choose the island Hillesøy located on the north coast of Norway $\left(69.65^{\circ} \mathrm{N}, 17.95^{\circ} \mathrm{E}\right)$ at the entrance to the Barents Sea, see Fig. 1. Monthly observations of ${ }^{99} \mathrm{Tc}$ has been conducted at this location since 1997 by the Norwegian Radiation Protection Authority (NRPA), and compar- ison with output from OGCMs have been presented in Karcher et al. (2004) and Orre et al. (2007).

Continuous releases from the two sources are expected to result in a quasi steady-state concentration at a location downstream if there is no recirculation or accumulation of tracers, which is a reasonable assumption for tracers transported northward with the $\mathrm{NCC} / \mathrm{NwAC}$ system on these timescales. The variation in concentration should then be the result of variable ocean dynamics. The simulated concentration from Sellafield and Dounreay at Hillesøy from 1997 and onward shares much of the same variability (Fig. $5)$. However, the transient state is very different in that tracers from Sellafield need a much longer time to reach this steady-state concentration.

The simulated time history of the age shows a steep 


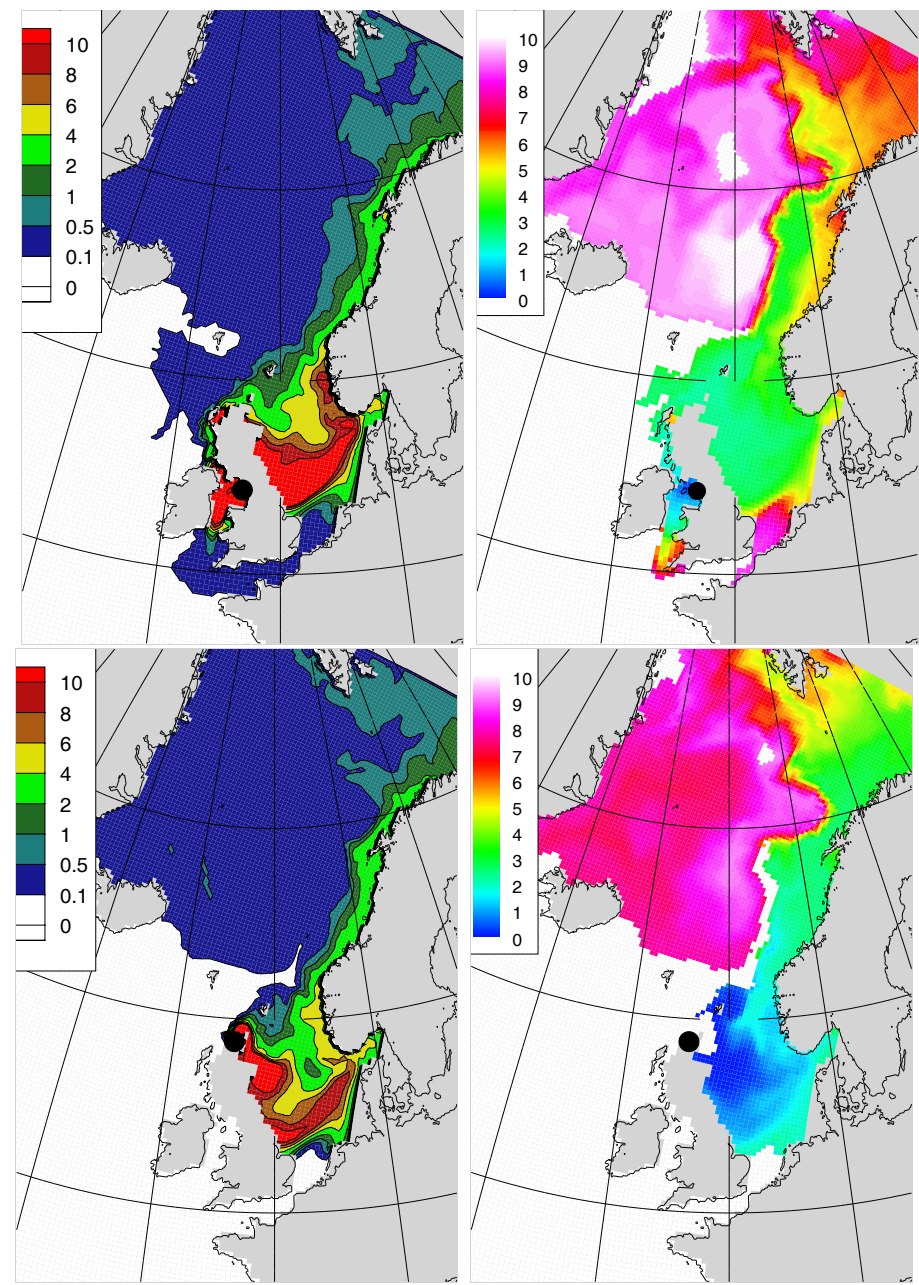

Fig. 4. Simulated surface values in March 2002 of (upper-left panel and lower-left panel) concentration (non-dimensional units: $\mathrm{m}^{-3}$ ) from the continuous release, and (upper-right panel and lower-right panel) the age (in years) of the tracers with continuous release rate. Upper panel displays tracers from Sellafield, lower panel tracers from Dounreay, source region indicated with the black dot.

growth from zero when the first patch of tracers arrive at Hillesøy. Thereafter the age grows steadily as a result of a mix of both old and relatively young water masses. The initial growth period before the age reaches a steady state is at least twice as long for Sellafied as the growth of the age from Dounreay (although it is difficult to precisely determine how long this period is). If we assume the age is close to a steadystate by the last 5 years of the simulation, the age at Hillesøy is $5-6$ years from the Sellafield-derived tracers and about 3 years from the Dounreay-derived tracers.

The pulse from Sellafield is smeared out for more than ten years at Hilles $\varnothing y$, in fact, the concentration doesn't vanish along the Norwegian coas within the simulation. This is in sharp contrast to the resulting concentration from the pulse released from Dounreay, where a steep increase is followed by a more gradual decrease. This effectively shows the profound difference of having the tracer source in the Irish Sea versus the more dynamic region on the northern coast of Scotland close to the persistently poleward flowing Atlantic waters, hence, the effect of a more unidirectional advection. Although these pulse releases cannot be directly linked to the TTD due to the time variability, as noted in section 3.1, it effectively shows how the initial pulse signal is stretched in time when transported from the source, and should therefore be representative of a typical distribution of ages at this location. From this we deduce that the typical spread of the TTD, typically called the width of the age distribution (Delhez and Deleersnijder, 2002), is much greater from Sellafield than from Dounreay. Furthermore, this 

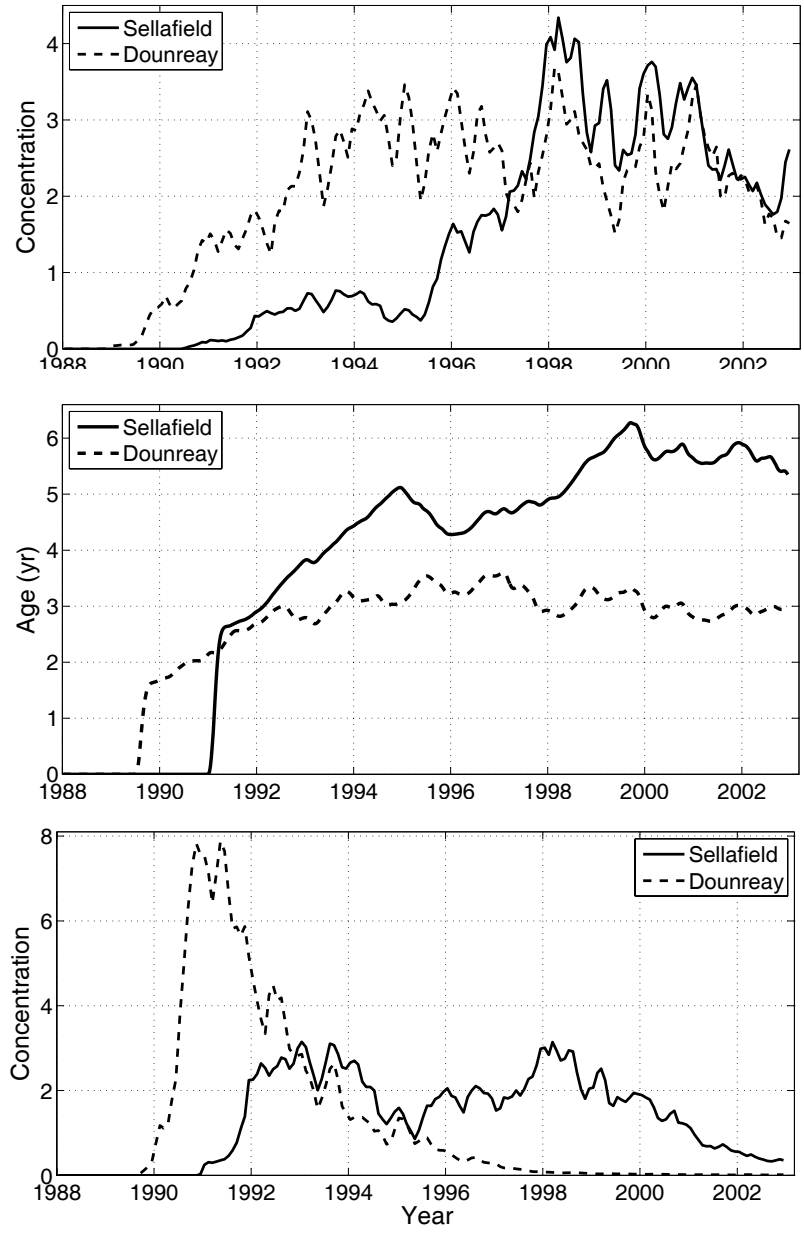

Fig. 5. (top) Simulated concentration at Hillesøy (nondimensional units $\mathrm{m}^{-3}$ ) from the continuous release, (middle) simulated age of the tracers with continuous release rate, and (bottom) simulated concentration from the pulse (1) release.

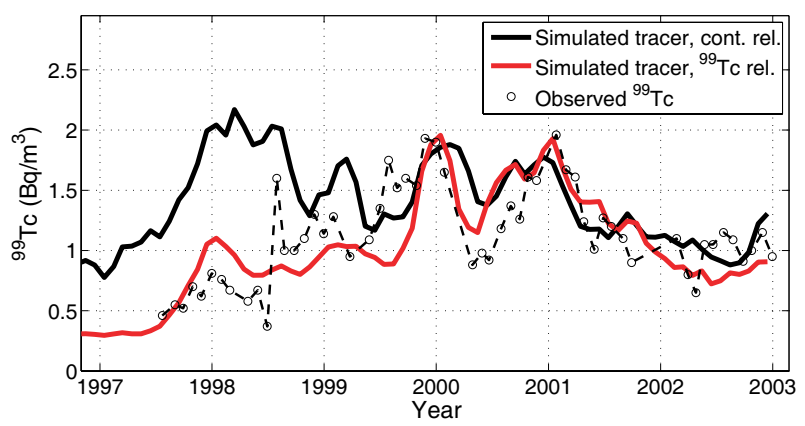

Fig. 6. Comparison of simulated tracer concentration with continuous release from Sellafield at Hilles $\varnothing$, and simulated and observed concentration of ${ }^{99} \mathrm{Tc}\left(\mathrm{Bq} \mathrm{m}^{-3}\right)$ at Hillesøy. The simulated tracer concentration with continuous release is divided by a factor of 2 to fit the values of ${ }^{99} \mathrm{Tc}$ at this place for this period. might also explain why the initial growth period of the age, as noted above, is about twice as long from Sellafield as from Dounreay.

We end this section with a qualitative comparison of the tracer with continuous release from Sellafield with observed and simulated concentration of ${ }^{99} \mathrm{Tc}$ at Hillesøy. The simulated ${ }^{99} \mathrm{Tc}$ concentration accounts for the release rates from both Sellafield and La Hague, which are the only nuclear fuel reprocessing plants which have released ${ }^{99} \mathrm{Tc}$. These two reprocessing plants exceed other sources such as fallout from nuclear bomb testing by more than two orders of magnitude. It should be noted that ${ }^{99} \mathrm{Tc}$ from La Hague is negligible compared to Sellafield after 1990 (Kershaw et al., 2004). The releases of ${ }^{99}$ Tc from Sellafield increased drastically in 1994, before a moderate reduction was reported from 1997 and onward (Orre et al., 2007). Both the observed and simulated concentration at Hillesøy peaked in the winter 2000 and 2001, after which a decrease is seen (Fig. 6). The figure clearly illustrates that the decrease of ${ }^{99} \mathrm{Tc}$, from approximately January 2001 and onwards, is not only caused by reduced releases from Sellafield in the late 1990s, but also the underlying ocean dynamics. The ideal tracer with continuous release from Sellafield also shows a decrease in the same period, and the correlation coefficient between these two simulated time series is as high as 0.8 for the period of 1999 to 2003. It is readily seen that this OGCM suggest a dominant role of the ocean dynamics in shaping the variability of the tracer signal rather than the release rate at a station downstream of the tracer source, although this certainly would depend on the distance from the source (the greater the distance from the source, the more of the original shape of the tracer signal from the release rate would be lost due to the continuous mixing processes occurring in the ocean).

\section{Summary}

A numerical experiment with idealized passive tracers from the locations of the nuclear fuel reprocessing plants at Sellafield in the Irish Sea and Dounreay on the northern coast of Scotland has been carried out. The objective has been to investigate some of the dispersion features of the tracers originating from both a semi-enclosed basin and also from the open ocean, and the following large-scale dispersion of the tracers.

It is found that tracers from Dounreay are rapidly carried away from the source region, first into the North Sea and then northward along the coast off Norway. The transport of Sellafield-derived tracers are, however, efficiently delayed from the release in the Irish Sea, leading to a qualitatively different dis- 
persion pattern. The age of tracers from Dounreay is approximately 2 years younger than the age from Sellafield in the Norwegian Sea. In addition, the initial growth period of the age from Sellafied is significantly longer compared to the age from Dounreay.

Although a continuous release of contaminants from both sources eventually reaches the same values in the far field, the transient state is very different. This is particularly evident from a pulse released from the two source regions, where the pulse from Dounreay shows a distinct peak value along the Norwegian coast a few years after the release, and then almost vanish from the entire Nordic Seas by the end of the simulation. The pulse from Sellafield, on the other hand, is effectively delayed by the fact that the release region is in a semi-enclosed basin, and the resulting maximum concentration along the Norwegian coast is less than half of the maximum concentration stemming from the Dounreay-derived pulse. We also conclude that the differences in tracer transport from Sellafield versus Dounreay cannot be characterized by a simple time lag in the resulting tracer concentration downstream of the source, due to the different transient state.

We argue that an order of magnitude higher value of the equivalent diffusion from the Dounreay site explains these qualitative differences. Calculating the single parameter equivalent diffusion has a potential for extracting crucial information from the vast output that an OGCM delivers. Therefore, information on the strength of the initial spreading near the source of contamination would be very useful, and even critical, for estimating the large-scale transport of any passive tracer release on the north-west European shelf region. We emphasize that for the near source distribution of tracers, the temporal evolution will critically depend on the ocean initial state and the actual atmospheric forcing. However, the estimated equivalent diffusion in this paper is based on a whole year of simulated tracer dispersion. A recent model study on radioactive tracers from Sellafield and La Hague suggests that the large scale dispersion properties are not very dependent on the release date (Orre, 2008).

From the timeseries at Hillesøy at the entrance to the Barents Sea, both from observed and simulated values of ${ }^{99} \mathrm{Tc}$ and simulated idealized tracers, it is readily seen that the ocean dynamics plays a dominant role in shaping the variability of the tracer signal rather than the release rate at a station downstream of the source region in the Irish Sea or the northern coast of Scotland.

The concept of age tracers, as developed by Deleersnijder et al. (2001) and Delhez and Deleersnijder (2002), is a diagnostic tool designed for numerical models, and can, in principle, be applied to any trac- ers with prescribed sources and sinks. For the concept of equivalent diffusion, as developed and used here, we emphasize that for this approach to be meaningful, the tracer dispersion should be mainly two-dimensional (or along surfaces of constant density), and that the decrease of the maximum tracer inventory should be proportional to the inverse of time, and the variance of the tracer distribution should grow proportional to time.

Acknowledgements. This study is a part of the Arctic Radioactive Contamination (ARC) project, funded by the Research Council of Norway. The authors are grateful to Eric Delhez for providing constructive comments on the paper, and to Morten Sickel from the NRPA, Norway, for providing the time series of observed concentration of ${ }^{99} \mathrm{Tc}$ in seawater at Hillesøy. Support from the G. C. Rieber Foundation is acknowledged. Eric Deleersnijder is a Research associate with the Belgian National Fund for Scientific Research (FNRS). This is contribution A 198 from the Bjerknes Centre for Climate Research.

\section{REFERENCES}

AMAP, 2004: Amap Assessment 2002: Radioactivity in the Arctic. Tech. Rep., Oslo, Norway, 320pp.

Beckers, J., E. Delhez, and E. Deleersnijder, 2001: Some properties of generalized age-distribution equations in fluid dynamics. SIAM Journal on Applied Mathematics, 61(5), 1526-1544.

Bleck, R., C. Rooth, D. Hu, andf L. Smith, 1992: Salinity-driven thermohaline transients in a windand thermohaline-forced isopycnic coordinate model of the North Atlantic. Journal of Physical Oceanography, 22, 1486-1515.

Dahlgaard, H., 1995: Transfer of European coastal pollution to the Arctic: Radioactive tracers. Marine Pollution Bulletin, 31, 3-7.

Davies, A., and P. Hall, 2000: The response of the North Channel of the Irish Sea and Clyde Sea to wind forcing. Continental Shelf Research, 20, 897-940.

Deleersnijder, E., J. Campin, and E. Delhez, 2001: The concept of age in marine modelling I. Theory and preliminary model results. Journal of Marine Systems, 28, 229-267.

Delhez, E., and E. Deleersnijder, 2002: The concept of age in marine modelling II. Concentration distribution function in the English Channel and the North Sea. Journal of Marine Systems, 31, 279-297.

Drange, H., R. Gerdes, Y. Gao, M. Karcher, F. Kauker, and M. Bentsen, 2005: Ocean General Circulation Modelling of the Nordic Seas. The Nordic Seas: An Integrated Perspective, AGU Monograph, 199-220.

Gao, Y., H. Drange, and M. Bentsen, 2003: Effects of diapycnal and isopycnal mixing on the ventilation of CFCs in the North Atlantic in an isopycnic coordinate OGCM. Tellus, 55B, 837-854.

Gao, Y., H. Drange, M. Bentsen, and O. Johannessen, 
2004: Simulating transport of non-Chernobyl ${ }^{137} \mathrm{Cs}$ and ${ }^{90} \mathrm{Sr}$ in the North Atlantic-Arctic region. Journal of Environmental Radioactivity, 71, 1-16.

Haine, T., and T. Hall, 2002: A generalized transport theory: Water-mass composition and age. J. Phys. Oceanogr., 32, 1932-1946.

Hatun, H., A. Sandoe, H. Drange, B. Hansen, and H. Valdimarsson, 2005: Influence of the Atlantic Subpolar Gyre on the Thermohaline circulation. Science, 309, 1841-1844.

Haynes, P., and E. Shuckburgh, 2000: Effective diffusivity as a diagnostic of atmospheric transport 1: Stratosphere. J. Geophys. Res., 105, 22777-22794.

Holzer, M., and T. Hall, 2000: Transit-time and tracerage distribution in geophysical flows. J. Atmos. Sci., 57, 3539-3558.

Karcher, M., S. Gerland, I. Harms, M. Iosjpe, H. Heldal, P. Kershaw, and M. Sickel, 2004: The dispersion of ${ }^{99} \mathrm{Tc}$ in the Nordic Seas and the Arctic Ocean: A comparison of model results and observations. Journal of Environmental Radioactivity, 74, 185-198.

Kershaw, P., H. Heldal, K. Mork, and A. Rudjord, 2004: Variability in the supply, distribution and transport of the transient tracer ${ }^{99} \mathrm{Tc}$ in the NE Atlantic. Journal of Marine Systems, 44, 55-81.

Marshall, J., E. Shuckburgh, H. Jones, and C. Hill, 2006: Estimates and implications of surface eddy diffusivity in the Southern Ocean derived from tracer transport. J. Phys. Oceanogr., 36, 1806-1821.

Morse, P., and H. Feshbach, 1953: Methods of Theoretical Physics, Part I. McGraw-Hill, 177-182.

Okubo, A., 1971: Oceanic diffusion diagrams. Deep-Sea Research, 8, 789-802.

Orre, S., 2008: Circulation features in the northern North Atlantic Ocean inferred from simulated radioactive tracers. Ph. D. dissertation, University of Bergen, 126pp.

Orre, S., B. Gjevik, and J. LaCasce, 2006: Characterizing chaotic dispersion in a coastal tidal model. Continental Shelf Research, 26, 1360-1374.

Orre, S., Y. Gao, H. Drange, and J. Nilsen, 2007: A reassessment of the dispersion properties of ${ }^{99} \mathrm{Tc}$ in the North Sea and the Norwegian Sea. Journal of Marine Systems, 68, 24-38.

Prandle, D., 1984: A modelling study of the mixing of ${ }^{137} \mathrm{Cs}$ in the seas of the European continental shelf. Philosophical Transaction of the Royal Society of London, 310, 407-436.

Waugh, D., T. Hall, and T. Haine, 2003: Relationships among tracer ages. J. Geophys. Res., 108(C5), 1-16.

Wiggins, S., 2005: The dynamical systems approach to Lagrangian transport in oceanic flows. Annual Review of Fluid Mechanics, 37, 295-328. 
Reproduced with permission of the copyright owner. Further reproduction prohibited without permission. 